\title{
Physiology of Growth Hormone Secretion
}

\author{
Aysun Bideci, Orhun Çamurdan \\ Gazi University Medical School, Pediatric Endocrinology Unit, Ankara, Turkey
}

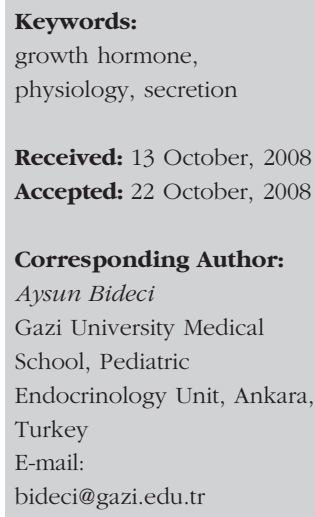

\section{ABSTRACT}

Growth hormone $(\mathrm{GH})$ is secreted in a pulsatile fashion from the anterior pituitary gland. The synthesis and the secretion of $\mathrm{GH}$ are regulated mainly by two hypothalamic neuropeptides, the growth hormone-releasing hormone $(\mathrm{GHRH})$ and somatostatin. A wide variety of physiologic and hormonal factors exert an effect on $\mathrm{GH}$ secretion.

This paper will review physiology of GH secretion and the factors that regulate it.

Conflict of interest: None declared

Growth hormone $(\mathrm{GH})$ is secreted in a pulsatile fashion from the anterior pituitary gland. GH has a 191-aminoacid peptide structure containing two disulphide bonds. It is found in the circulation in different isoforms of which the 20 and the relatively more active $22 \mathrm{kd}$ isoforms are biologically more important. There are 5 known genes related to the $\mathrm{GH}$ molecule of which the GH-N, the main gene, has the locus on 17q22-24. The others are the GH-2 (GH-V) coding for placental GH, the CS1 and CS2 coding for the human chorionic somatomammotropin, and the pseudogene CSP.(1, 2, 3, 4)

$\mathrm{GH}$ exists in two forms in the circulation, in the free, active form and the bound from which is bound to the growth hormone binding protein (GHBP),(1) without loss of immunoreactivity so that the measured GH levels reflect the levels of both forms.(5)

The synthesis and the secretion of GH SUPPLEMENT are regulated by two hypothalamic neu- ropeptides; the growth hormone-releasing hormone (GHRH) and somatostatin or the somatotropin release inhibiting factor. GHRH stimulates both the synthesis and the release of GH. It is the amplitude and not the frequency of the pulsatile release that is changed. Somatostatin has no effect on the synthesis but inhibits the release of GH.(1, 2, 3, 4) In the rat, administration of somatostatin antibody resulted in an increase of the GH levels between the pulses without an effect on the freqency of the pulses. In humans, in both male and female, endogenous somatostatin suppresses the GH levels between the pulses and the amplitude of the pulses but, again, without a change in the frequency of the pulses. These observations have led to the conclusion that in the human the biological role of somatostatin is limited to the adjustment of the quantity of the basal and the pulsatile secretion of GH without alteration of the pulse rate.(2) 
Those agents which influence the secretion of GH act through their effects on the release of GHRH and somatostatin. The $\alpha_{2^{-}}$ adrenergic agonists, dopaminergic agonists, clonidine and levodopa increase the release of GHRH, while pyridostigmine and cholinergic agents achieve augmentation of $\mathrm{GH}$ levels through the inhibition of somatostatin release. $(6,7)$ Insulin induced hypoglycaemia and arginine infusion result in an increased $\mathrm{GH}$ release through both of these mechanisms. The latest studies have shown, however, that GHRH receptor agonists significantly inhibit the acute GH response to the stimulatory effects of pyridostigmine, clonidine, levodopa, arginine, insulin induced hypoglycaemia and the synthetic ghrelin agonist growth hormone releasing peptide (GHRP-6).(1, 5)

Insulin-like growth factor (IGF)-I, the end product of $\mathrm{GH}$ bioeffect, has a negative feedback effect on GH secretion. IGF-I stimulates the hypothalamic release of somatostatin and has been observed in hypophyseal cultures to inhibit the GHRH-dependent $\mathrm{GH}$ release by direct action. (4) In addition to the influence of IGF-I, the quantity and the pattern of release of $\mathrm{GH}$ are also dependent on the nutritional state, type of foods ingested and the gonadal steroid environment. The role of ghrelin is also under consideration. Thyroid hormones are known to influence GH levels and they act via the receptors on the cell nuclei by stimulating the transcription of GH. (1, 2, 4)

Although GH exerts its biological function through the IGF system, both GH and IGF-I have been shown to have specific effects. Accordingly, GH and IGF-I influence growth at different stages of cell maturation.(1, 4) $\mathrm{GH}$ is effective on the growth plate and the osteoblasts both directly and indirectly, through the IGF system.

The indirect effects of $\mathrm{GH}$ are exerted primarily through IGF-I. In the liver and other tissues (e.g., the epiphyses and the muscle), GH increases the synthesis of IGFI, IGF bindig protein (IGFBP)-3 and the acid labile subunit (ALS). The direct effect of GH is mostly on the adipose tissue.(8)

The specific receptor of GH (GHR) is a 638-aminoacid protein, a receptor of the extrinsic tyrosine kinase group encoded on chromosome 5. It consists of an extracellular part to bind $\mathrm{GH}$, a transmembranal sequence and a cytoplasmic part. The GHBP is the proteolytic part of the extracellular sequence of GHR and it probably released to the circulation by the action of a tumour necrosis factor (TNF- $\alpha$ ) converting enzyme.(9) Thus, information can be obtained on GHR by measuring the GHBP level.(5) GHBP plays a regulatory role on the inhibition and activation of the release of the bound $\mathrm{GH}$ and its distribution to the tissues. GHBP levels are decreased in diabetes mellitus (DM), malnutrition, hypothyroidism, liver disease and are increased in obesity and estradiaol $\left(\mathrm{E}_{2}\right)$ therapy. $(2,8)$ The sequence of events following binding of GH to GHR has been discussed in detail in another paper by Tarım in this Supplement.

\section{GHRH}

It was first demonstrated in rats that somatic growth was retarded in the absence of an intact hypothalamus. Subsequently the hypothalamic ventromedial nucleus was shown to be the site responsible for the regulation of GH release. $(2,4,7)$ GHRH-mediated binding of guanidine triphosphate (GTP) to the $\alpha$-unit of the G-protein (Gs) activates the Gs, resulting sequentially in increased cyclic adenosine-mono-phosphate(cAMP), changes in the intracellular balance of $\mathrm{Na}^{+}$and $\mathrm{Ca}^{++}$ions and the secretion of GH.(10) The neutralisation of GHRH has been shown to have different effects in the female and the male rat, indicating a difference in the control of $\mathrm{GH}$ release in the two sexes.(2) While this neutralisation prevented the formation of $\mathrm{GH}$ release pulses without a concurrent change in the quantity of the basal GH release between the pulses in the male, in the female the tonic inter- 
pulse GH levels were also lowered. In humans there are other gender differences with respect to GH secretion. Although total 24 hours $\mathrm{GH}$ release is nearly equal in both sexes; in males most of the GH release occurs in the early hours of the night with a hypopulsatile release during the day hours with low basal levels. In the young female, on the other hand, multiple day time secretory episodes occur with high basal levels, but relatively lower nocturnal release. $(2,11)$ A higher $\mathrm{GH}$ secretory response to GHRH has been observed in women.

The sensitivity to GHRH antagonists is also different between the human male and female. In the female sensitivity is higher during the night and the continuity of the basal secretion is highly dependent on GHRH.(1, 12)

The decrease in GH secretion with age is described as the somatopause. In the aged individual, despite the reduction of the $\mathrm{GH}$ pulse amplitude, the $\mathrm{GH}$ releasing response to exogenous GHRH is intact, suggesting that age-related fall in the $\mathrm{GH}$ levels is associated with reduction in the hypothalamic GHRH response.(1, 6, 13) There are arguments, however, that age-related decrease in $\mathrm{GH}$ levels is associated with hypersecretion of somatostatin and obesity.(2)

\section{SOMATOSTATIN}

The 14-aminoacid peptide somatostatin is an inhibitory regulator of $\mathrm{GH}$ secretion acting as an endocrine, autocrine and paracrine hormone. It is released from both hypothalamic neurons and the D cells of the pancreatic islets of Langerhans. It has an inhibitory effect on the release of TSH, ACTH, LH, FSH and prolactin as well as a local inhibition of the gastrointensinal hormones, namely, secretin, gastrin and the vasoactive intestinal peptide (VIP). Of the five types of somatostatin receptors types 2 and 5 are the most effective on GH release inhibition.(1, 2, 3) In addition to inhibiting spontaneous GH release, GHRH, hypogly- caemia, arginine and exercise stimulated GH release are also inhibited by these receptors. Its halflife is very short (only 3 minutes). After the termination of somatostatin infusion, spontaneous $\mathrm{GH}$ immediately peaks up, while the response to GHRH is significantly augmented indicating that somatostatin has no direct effect on the biosynthesis of GH but merely blocks the secretory mechanism resulting in an accumulation of the hormone within the somatotrophic cells during the infusion. In the human, the rebound in GH release after somatostatin does not require the presence of GHRH. This finding has led to the postulation that GHRH and somatostatin are responsible for the rhythmic release of GH.(1, 2, 14, 15, 16)

\section{GHRELIN}

Ghrelin consists of 28 aminoacids with a serine at the no. 3 position of the primary structure which has to be octanoylated for hormonal action. It is mainly secreted in the stomach, but also secreted in the hypothalamic arcuate nucleus, the heart, the liver and the pancreas. Ghrelin has a rate increasing effect on GH release after entering the general circulation via different ways or after release in the central nervous system (CNS)(1), as shown by the augmentive effect of synthetic ghrelin analogues (GHS) alone or together with GHRH. It is debated that GHS are functionally somatostatin antagonists and the GHRH receptors have to be fully functionally occupied for full effect on the secretion of GH. Continuous GHS infusion results in homologue desensitization despite elevated GH pulses and augmented response to GHRH which indicates a cross-reaction between GHRH and ghrelin. However, a role of endogenous ghrelin on basal GH release is doubtful. During fasting, despite the lack of increase in ghrelin or the octanoylated ghrelin levels, GH secretion is significantly increased.(17, 18) Furthermore, there is a lack of an increase in GH levels in the presence of ghrelin releasing tumours in 
humans, and there is no change in the rate of body growth in animal models with blocked ghrelin or the ghrelin receptor genes. $(2,19)$ These findings have supported the conclusion that ghrelin in the hypothalamo-hypophyseal axis or in the systemic circulation does not contribute significantly to the physiological control mechanisms of GH secretion.

\section{REGULATION OF GH SECRETION BY FEEDBACK MECHANISMS}

Feedback mechanisms are effective on different stages of GH secretion. GH itself as well as GHRH and somatostatin can be considered to be effective on short term feedback. Hypophyseal GH, while inhibiting GHRH secretion can stimulate somatostatin secretion. GHRH has a negative feedback effect on its own stimulatory action. Low dose GHRH given to the cerebral ventricles results in the inhibiton of GH release. GHRH also causes inhibiton by stimulating somatostatin secretion which has the ability to suppress its own neuronal release as well as inhibiting the release of GHRH. $(1,2)$

The longterm feedback control of $\mathrm{GH}$ secretion is exerted by the terminal products of GH activity like IGF-I. Laron et al(8) have observed significantly increased GH levels in individuals with genetic defects of IGF-I production. $^{8}$ The suppressive control of $\mathrm{GH}$ release by IGF-I is similar in both sexes, but gender-dependent responses have been observed in the presence of exogenous GHRH such that, a significant increase in the inhibition of GH relase is seen in the male but not in the female. The observation in the males is attributed to stimulation of somatostatin secretion. In the female IGF-I is believed to suppress GHRH release.(1, 2, 3)

\section{FASTING}

Fasting causes a reduction of the free and total IGF-I concentrations in blood. During the first 24 hours of fasting the plas- ma levels of $\mathrm{GH}$ rise 2-3 fold and reach a plateau after the third day.(1) This increase has been observed to be restricted to $\mathrm{GH}$ pulse amplitude without a significant change in the pulse frequency or the interpulse $\mathrm{GH}$ concentrations. During fasting GH response to GHRH remains at a minimum level, all observations indicating that fasting-related changes in GH release depend on the induction of GHRH expression.(2)

\section{SLEEP}

GH level reaches its 24-hour peak during sleep. This rise is related to the internal dynamics of sleep, taking place during the slow wave stage of sleep and shortly after falling asleep. The sleep-dependent GH release is more significant in men than in women. $(7,11)$

The mechanisms underlying the sleeprelated GH release have not been completely elucidated. The simplest explanation given is the reduced suppressive effect of corticosteroids on GH release. Associated with the nocturnal fall in the corticosteroid levels GH levels rise; however this explanation suffers mainly from the lack of correlation between the nocturnal rhythms of the glucocorticoids and of GH.(2) The proposal that the rise in $\mathrm{GH}$ release is associated with the nutrients ingested has been invalidated by the observation that the sleeprelated rise in $\mathrm{GH}$ level was unaltered after one week of fasting. One possible causative agent may be GHRH. Although in cases with an inactivating mutation in the GHRH receptor the sleep-related $\mathrm{GH}$ rise does occur, continuous infusion of GHRH antagonists results in significant reduction in this phase of GH release. However, this finding has not provided a clear-cut explanation of the mechanism underlying the increase in nocturnal GH release. The role of combined actions of GHRH and somatostatin have also been speculated. Studies have shown that GH response to GHRH changes with the hours of the day. The response is 
the lowest between 08:00 and 14:00 hours, slowly rising to peak levels between 22:00 and 02:00 hours, and gradually falling thereafter to the morning levels. This modulation of release has been thought to result from the diurnal pattern of somatostatin release. However, the infusion of octreotide (a synthetic octapeptide that mimics natural somatostatin with a potent inhibitory effect on major endocrine release mechanisms) in healthy adults has not affected the sleep-related rise in GH release despite a significant fall in the total $\mathrm{GH}$ released in 24 hours, suggesting the irrelevance of somatostatin to the nocturnal rise of GH release. $(2,20)$ Ghrelin does not have a control on the nocturnal change in $\mathrm{GH}$ release because endogenous ghrelin levels do not demonstrate a diurnal rhythm.

\section{GONADAL STEROIDS}

Parallel to the pubertal rise and agedependent fall in the levels of gonadal steroids, GH and IGF-1 levels also show an increase and a decrease respectively. The physiological mechanism underlying the differences in the male and female responses of $\mathrm{GH}$ release to different stimulants may depend on the differing actions of the androgens and estrogens on the GH axis.(1, 21) Studies utilising androgen and estrogen receptor blockers show that the female hormones act directly on $\mathrm{GH}$ release, whereas the androgens are effective after aromatisation to estrogens. Indeed, testosterone, which is aromatisable to estrogen, causes escalation of the GH pulse amplitudes, the non-aromatisable dihydrotestosterone or the synthetic oxandrolone (oxandrin) are ineffective on this kind of release. $(1,2)$

Although the mechanism of action of the gonadal steroids is not clear, there is consensus that it does not involve the GHRH and somatostatin dependent interactive mechanisms. For example, in boys with delay of pubertal development, the increase in $\mathrm{GH}$ release observed after the administration of exogenous testosterone cannot be prevented with GHRH receptor antagonists. (2, 22)

The role of gonadal steroids on the hepatic IGF-I biosynthesis is very intricate. Giving exogenous dihydrotestosterone to female rats devoid of endogenous gonadal steroids has caused an increase in the hepatic IGF-I mRNA as well as in plasma IGF-I and hypophyseal GH levels, while the plasma levels of $\mathrm{GH}$ decreased. Treating the same rats with oestradiol, on the other hand, has resulted in exactly opposite effects. Similar observations on the effect of estrogen on the intracellular GH signalling mechanisms has indicated an inhibitory effect of the steroid on IGF-I synthesis.(22)

\section{NUTRITIONAL EFFECTS}

Hyperglycaemia, following an initial and temporary suppression of GH levels leads to an increase in GH levels. The initial suppressive effect is probably due to an increase in somatostatin release similar to that observed when glucose loading is simultaneous to GHRH and GHS infusion. The reversal of this acute suppression is due to the reduction in somatostatin release and the resultant activation of GHRH release.(23, 24) Hypoglycaemia, on the other hand, causes an acute increase in $\mathrm{GH}$ secretion which requires an intact GHRH signalling system.(5)

Free fatty acids (FFA), similar to hyperglycaemia, cause an inhibition of GH release by somatostatin. In conditions like obesity with chronically elevated FFA levels, GH levels are suppressed.

Acipimox (a niacin derivative used as a hypolipidemic agent) by inhibiting FFA release causes an increase in the basal as well as the GHRH stimulated GH secretion.(24) In obesity, in addition to the inhibitory effect of FFA on GH release, the negative feedback of increased IGF-I secondary to IGFBP-I decrease, and the increased tone of somatostatin release also contribute to the suppression of the relase of 
GH. During fasting, despite the rise in the FFA levels, contrary to the expectations, GH levels are increased. This might be a consequence of the strong activation of $\mathrm{GH}$ release by the low IGF-I levels during fasting. $(1,2)$
In conclusion, the somatotrope axis and the intricately interrelated actions of the related physiological factors indicate the need for the continuation of the current investigations on this very important area of the endocrine system.

\section{REFERENCES}

1. Rosenbloom AL, Connor LE. Hypopituitarism and other disorders of the growth hormone-insulinlike growth factor I axis. In: Lifshitz F (ed), Pediatric Endocrinology, 3rd ed, New York, Informa Health Care 2007; 65-101.

2. Goldenberg N, Barkan A. Factors regulating growth hormone secretion in humans. Endocrinol Metab Clin North Am 2007;36: 37-55. [Abstract]

3. Hirt H, Kimelman J, Birnbaum MJ, Chen EY, Seeburg PH, Eberhardt NL, Barta A. The human growth hormone gene locus: structure, evolution, and allelic variations. DNA 1987;6:59-70. [Abstract]

4. Abrams RL, Parker ML, Blanco S, Reichlin S, Daughaday WH. Hypothalamic regulation of growth hormone secretion. Endocrinology 1966;78:605-613. [Abstract]

5. Sills RH. Failure to thrive. The role of clinical and laboratory evaluation. Am J Dis Child 1978;132:967-969. [Abstract]

6. Tenenbaum-Rakover $Y$. The need to revise the cut-off level for the diagnosis of GH deficiency in children. Pediatric Endocrinol Rev 2008; 5:880-888. [Abstract]

7. Frohman LA, Bernardis LL, Kant KJ. Hypothalamic stimulation of growth hormone secretion. Science 1968;162:580-582.

8. Maccario M, Grottoli S, Procopio M, Oleandri SE, Rossetto R, Gauna C, Arvat E, Ghigo E. The GH/IGF1 axis in obesity: influence of neuro-endocrine and metabolic factors. Int J Obes Relat Metab Disord 2000; 24 (Suppl 2): S96-S99. [Abstract]

9. Bougnères $P$, Goffin $V$. The growth hormone receptor in growth. Endocrinol Metab Clin North Am 2007; 36:1-16. [Full Text / PDF]

10. Goth MI, Lyons CE, Canny BJ, Thorner MO. Pituitary adenylate cyclase activating polypeptide, growth hormone $(\mathrm{GH})$-releasing peptide and $\mathrm{GH}$-releasing hormone stimulate $\mathrm{GH}$ release through distinct pituitary receptors. Endocrinology 1992;130:939-944. [Abstract / Full Text]

11. Jaffe CA, Ocampo-Lim B, Guo W, Krueger K, Sugahara I, DeMott-Friberg R, Bermann M, Barkan AL. Regulatory mechanisms of growth hormone secretion are sexually dimorphic. J Clin Invest 1998;102:153-164. [ Full Text / PDF]

12. Jessup SK, Dimaraki EV, Symons KV, Barkan AL. Sexual dimorphism of growth hormone $(G H)$ regulation in humans: endogenous $\mathrm{GH}$-releasing hormone maintains basal $\mathrm{GH}$ in women but not in men. J Clin Endocrinol Metab 2003;88:4776-4780. [Abstract / Full Text / PDF]

13. Russell-Aulet M, Dimaraki EV, Jaffe CA, DeMott-Friberg R, Barkan AL. Aging-related growth hormone $(\mathrm{GH})$ decrease is a selective hypothalamic $\mathrm{GH}$-releasing hormone pulse amplitude mediated phenomenon. J Gerontol A Biol Sci Med Sci 2001;56:M124-129. [Abstract]

14. Vance ML, Kaiser DL, Martha PM Jr, Furlanetto R, Rivier J, Vale W, Thorner MO. Lack of in vivo somatotroph desensitization or depletion after 14 days of continuous growth hormone $(\mathrm{GH})$ releasing hormone administration in normal men and a GH-deficient boy. J Clin Endocrinol Metab 1989; 68:22-28. [Abstract]

15. Jaffe CA, DeMott-Friberg R, Barkan AL. Endogenous growth hormone (GH)-releasing hormone is required for $\mathrm{GH}$ responses to pharmacological stimuli. J Clin Invest 1996;97:934-940. [Full Text / PDF]

16. Plotsky PM, Vale W. Patterns of growth hormone-releasing factor and somatostatin secretion into the hypophysial-portal circulation of the rat. Science 1985;230:461-463. [Abstract] 
17. Kojima M, Hosoda H, Date Y, Nakazato M, Matsuo H, Kangawa K. Ghrelin is a growth- hormonereleasing acylated peptide from stomach. Nature 1999; 402:656-660. [Abstract]

18. Pandya N, DeMott-Friberg R, Bowers CY, Barkan AL, Jaffe CA. Growth hormone (GH)-releasing peptide- 6 requires endogenous hypothalamic $\mathrm{GH}$-releasing hormone for maximal GH stimulation. J Clin Endocrinol Metab 1998;83:1186-1189. [Abstract / Full Text / PDF]

19. Corbetta S, Peracchi M, Cappiello V, Lania A, Lauri E, Vago L, Beck-Peccoz P, Spada A. Circulating ghrelin levels in patients with pancreatic and gastrointestinal neuroendocrine tumors; identification of one pancreatic ghrelinoma. J Clin Endocrinol Metab 2003;88:3117-3120. [Abstract / Full Text / PDF]

20. Dimaraki EV, Jaffe CA, Bowers CY, Marbach P, Barkan AL. Pulsatile and nocturnal growth hormone secretions in men do not require periodic declines of somatostatin. Am J Physiol Endocrinol Metab 2003;285:E163-E170. [Abstract / Full Text]

21. Borski RJ, Tsai W, Demott-Friberg R, Barkan AL. Induction of growth hormone (GH) mRNA by pulsatile GH-releasing hormone in rats is pattern specific. Am J Physiol Endocrinol Metab 2000;278:E885-E891. [Abstract / Full Text]

22. Meinhardt UJ, Ho KKY. Regulation of growth hormone action by gonadal steroids. Endocrinol Metab Clin North Am 2007;36:57-73. [Full Text / PDF]

23. Yalow RS, Goldsmith SJ, Berson SA. Influence of physiologic fluctuations in plasma growth hormone on glucose tolerance. Diabetes 1969;18:402-408. [Abstract]

24. Broglio F, Benso A, Gottero C, Prodam F, Grottoli S, Tassone F, Maccario M, Casanueva FF, Dieguez $C$, Deghenghi R, Ghigo E, Arvat E. Effects of glucose, free fatty acids or arginine load on the GH-releasing activity of ghrelin in humans. Clin Endocrinol 2002;57: 265-271. [Abstract / Full Text / PDF] 